\title{
Understanding and Combating Misperceived Polarization
}

\author{
Jeffrey Lees ${ }^{1 *} \&$ Mina Cikara ${ }^{2}$ \\ ${ }^{1}$ Department of Economics, Clemson University, Wilbur O. and Ann Powers Hall, Clemson, SC 29634, ORCID: \\ 0000-0001-6030-4207. '2Department of Psychology, Harvard University, William James Hall, Cambridge, MA 02138, \\ ORCID: 0000-0002-6612-4474. \\ *Author Correspondence (jeffrey.m.lees@gmail.com). \\ Published in: Philosophical Transactions of the Royal Society $B$ \\ DOI: https://doi.org/10.1098/rstb.2020.0143
}

Cite as:

Lees, J., \& Cikara, M. (2021). Understanding and combating misperceived polarization. Philosophical Transactions of the Royal Society B, 376(1822), 20200143.

Keywords: polarization, intergroup relations, meta-perception, social psychology, politics

\begin{abstract}
By many accounts politics is becoming more polarized, yielding dire consequences for democracy and trust in government. Yet a growing body of research on so-called "false polarization" finds that perceptions of "what the other side believes" are inaccurate-specifically, overly pessimistic-and that these inaccuracies exacerbate intergroup conflict. Through a review of existing work and a reanalysis of published data, we (i) develop a typology of the disparate phenomena that are labeled "polarization," (ii) use that typology to distinguish actual from (mis)perceived polarization, and (iii) identify when misperceived polarization gives rise to actual polarization (e.g., extreme issue attitudes and prejudice). We further suggest that a specific psychological domain is ideal for developing corrective interventions: meta-perception, one's judgment of how they are perceived by others. We review evidence indicating that correcting meta-perception inaccuracies is effective at reducing intergroup conflict, and discuss methods for precisely measuring meta-perception accuracy. We argue that the reputational nature of meta-perception provides a motivational mechanism by which individuals are sensitive to the truth, even when those truths pertain to the "other side." We conclude by discussing how these insights can be integrated into existing research seeking to understand polarization and its negative consequences.
\end{abstract}




\section{Introduction}

Concerns about political polarization and its negative effects on democracy and intergroup relations have increased among scholars, policy makers, and the public alike over the past few years (Armaly \& Enders, 2020; Federico, 2020; lyengar et al., 2019; Moore-Berg, Hameiri, et al., 2020). Yet despite this attention to polarization as a major contributor to modern political ills, a growing body of scientific work on "false polarization" has simultaneously flourished, suggesting the extent of polarization is largely a fiction of our minds (Blatz \& Mercier, 2018; Druckman et al., 2019; Levendusky \& Malhotra, 2016; Westfall et al., 2015).

So are we actually quite polarized or do we just think we are? The answer, ultimately, is it depends. Of course there is a temptation when we think about polarization and its negative consequences to champion interpartisan harmony, but a well-functioning democracy requires disagreement and debate. Thus our aim is to promote belief accuracy regarding the true levels of polarization and the true attitudes of outgroups. But before we get to that we need to disentangle the myriad phenomena that are labeled "polarization" and understand their psychological roots.

Here we argue that integrating the psychology of meta-cognition-beliefs about what other people believe-will help us better understand polarization. First, we construct a typology of psychological and intergroup phenomena that, while distinct, have all been labeled "polarization." With this typology, we argue that what is commonly called "false polarization" is best understood as inaccurate meta-cognitive beliefs of the first-order ("what they believe") and second-order ("what they believe about us"). However, the term "false polarization" is misleading: polarization is a real, measurable phenomenon in the world. As we will review, what is false is people's beliefs about the extent of that polarization. To avoid confusion and facilitate conceptual clarity, we argue that the term "false polarization" should be replaced with "misperceived polarization."

We then highlight a growing body of work indicating that inaccurate perceptions of polarization can nonetheless drive actual polarization. To bolster our claim that inaccurate meta-cognition is a significant driver of actual polarization, we conduct a novel reanalysis of published data on intergroup meta-cognitive biases to demonstrate how psychological methods for measuring judgment accuracy can be utilized to better understand misperceived polarization and its relationship to actual polarization. We conclude by arguing that interventions designed to target inaccurate meta-perceptions may be particularly effective at reducing inaccurate perceptions of polarization and their negative effects due to the reputationally-relevant nature of second-order beliefs (i.e., that they are about "me" or "us").

\section{A Typology of Polarization, Actual and (Mis)Perceived}

As research in this area has flourished across multiple social science disciplines, many distinct phenomena across differing levels of analysis have been labeled "polarization." For example, polarization, specifically affective polarization, is often operationalized as the extremity of an individual's prejudice toward a political outgroup (e.g., lyengar et al., 2019; Simas et al., 2020; Stone, 2020). Other times, polarization is defined as individuals' ideological or 
issue-position extremity (e.g., Rollwage et al., 2018; Stanley et al., 2019), or as the strength of their partisan ingroup identification (e.g., Mason, 2018). Sometimes polarization is defined as these phenomena at an intergroup rather than individual level of analysis. That is, polarization is the empirical gap in ideology, outgroup attitudes, or ingroup identification between parties (e.g., Enders \& Armaly, 2018; Navajas et al., 2019; Porter \& Schumann, 2018).

Yet a third class of polarization phenomena refer to individuals' beliefs about outgroup individuals' positions or the intergroup gaps (e.g., Armaly \& Enders, 2020; Levendusky \& Malhotra, 2016; Westfall et al., 2015). For example, there are several documented cases in which people harbor overly negative beliefs about what the "other side" believes (e.g., Blatz \& Mercier, 2018; Van Boven et al., 2012; Yang et al., 2016). The term "false polarization" seems to have arisen from research on "naive realism" showing that partisans overestimate disagreement with outgroups (see Pronin et al., 2002; Robinson et al., 1995).

While many individual papers make these distinctions between different types of polarization (e.g., "actual vs. perceived", "affective vs. ideological") the absence of an organizing framework not only makes synthesis of the literature difficult, it makes discussing "false polarization" all the more confusing. In order for something to be "false," there must be a corresponding true value to which it is compared. To distinguish between polarization which relates to objective features of people and the world (actual polarization), and polarization that is a subjective perception which may or may not be accurate (perceived polarization), we propose a typology of phenomena called "polarization" in Table 1, which delineates between four levels of analysis and three domains of psychological processes.

Table 1: Phenomena Called "Polarization"

Level of Analysis

\begin{tabular}{|c|c|c|c|c|}
\hline & \multicolumn{2}{|c|}{$\begin{array}{c}\text { ACTUAL POLARIZATION } \\
\begin{array}{c}\text { Objective attributes of people and } \\
\text { intergroup relations }\end{array}\end{array}$} & \multicolumn{2}{|c|}{$\begin{array}{l}\text { (MIS)PERCEIVED POLARIZATION } \\
\text { Subjective perceptions of people and } \\
\text { intergroup relations (meta-cognition) }\end{array}$} \\
\hline & $\begin{array}{l}\text { Individual } \\
\text { positions }\end{array}$ & Intergroup gaps & 1st order beliefs & $\begin{array}{l}\text { 2nd order beliefs } \\
\text { (meta-perception) }\end{array}$ \\
\hline Ideology & $\begin{array}{l}\text { Issue-position } \\
\text { extremity }\end{array}$ & $\begin{array}{l}\text { The actual "Partisan } \\
\text { Gap" on issues, } \\
\text { ideological } \\
\text { polarization }\end{array}$ & $\begin{array}{l}\text { Perceived outgroup } \\
\text { extremism } \\
\text { Assumed } \\
\text { disagreement, } \\
\text { perceptions of the } \\
\text { "Partisan Gap" }\end{array}$ & $\begin{array}{l}\text { What I think they } \\
\text { think I believe: } \\
\text { ideological meta } \\
\text { perceptions, felt } \\
\text { misunderstanding }\end{array}$ \\
\hline Identity & $\begin{array}{l}\text { Partisan } \\
\text { identification } \\
\text { extremity }\end{array}$ & $\begin{array}{l}\text { Actual bimodal } \\
\text { distribution of } \\
\text { identification }\end{array}$ & $\begin{array}{l}\text { How I think other } \\
\text { people identify with } \\
\text { their party } \\
\text { My belief about the } \\
\text { size of the party } \\
\text { identification gap }\end{array}$ & $\begin{array}{l}\text { How I think they } \\
\text { think I identify: meta } \\
\text { stereotypes }\end{array}$ \\
\hline
\end{tabular}




\begin{tabular}{|l|l|l|l|l|}
\hline $\begin{array}{l}\text { Outgroup } \\
\text { Feelings, } \\
\text { Attributions }\end{array}$ & $\begin{array}{l}\text { Prejudice, } \\
\text { dehumanization of } \\
\text { outgroups, affective } \\
\text { polarization }\end{array}$ & $\begin{array}{l}\text { Actual tribalism, true } \\
\text { intergroup animosity }\end{array}$ & $\begin{array}{l}\text { Negative motive } \\
\text { attributions, } \\
\text { assumed distrust }\end{array}$ & $\begin{array}{l}\text { How I think they feel } \\
\text { about us/our } \\
\text { actions: group meta } \\
\text { perceptions, meta } \\
\text { dehumanization }\end{array}$ \\
\hline
\end{tabular}

In Table 1, individual and intergroup phenomena, such as one's own political issue position or outgroup prejudice, are objective features of individuals' psychology and social relations, respectively. Meta-cognitive beliefs, by contrast, are subjective perceptions of how I see "them" or the gaps between us (first-order beliefs), and perceptions of how we think "they" see "us" (second-order beliefs; what we call meta-perceptions). The critical insight here is that (i) so-called "false polarization" is solely the domain of meta-cognitive beliefs (the right two columns), and (ii) the distinction between "false" and actual polarization is more a distinction between levels of analysis (states of the world/people vs. perceptions of those states), not between phenomena that do or do not exist.

We also break these phenomena down by three psychological processes along the rows in Table 1. Ideological processes relate to phenomena that are issue oriented, including extremism, naive realism, and perceived intergroup disagreement. Identity processes relate to the strength of identification with social groups (e.g., political parties) for the self, fellow ingroup members, and the outgroup. Outgroup feelings and attributions are phenomena that are generally other-focused, domain/issue-general, and affective, including prejudice, distrust, and assumed negative reciprocity.

\section{How Inaccuracy in First vs. Second-Order Beliefs Lead to Actual Polarization}

Table 1 highlights the manner in which (mis)perceived polarization is conceptually distinct from other forms of polarization, but also how (mis)perceived polarization can refer to two distinct meta-cognitive judgments: inaccurate first-order beliefs about how others identify or how far apart two groups are on an issue (e.g., perceived partisan gap), and inaccurate second-order beliefs about what others think about oneself and one's group (meta-perceptions). This distinction not only helps us integrate disparate findings across the literature, it begins to illuminate the way in which inaccuracies in first vs. second order judgments may arise from different mechanisms.

First-order beliefs. Understanding inaccurate first-order beliefs is paramount, as such inaccuracies have been linked to a host of negative intergroup outcomes. For example, perceived out-party polarization (measured as perceived outgroup policy attitude extremity) is more strongly associated with negative outgroup evaluations than is perceiver's level of actual polarization (their own policy preferences; Enders \& Armaly, 2018). Similarly, partisans vastly overestimate the levels of party-stereotypic membership (e.g., the percentage of Democrats who are LGBT); these inaccurate perceptions correlate with out-party dislike and participants' feelings of social distance from out-party members (Ahler \& Sood, 2018). Partisans also underestimate how much they agree with out-party member views, which drives overestimation of the negative affect associated with exposure to opposing views and reduced consumption of opposing views (Dorison et al., 2019). 
Several scholars have begun to investigate whether correcting first-order belief inaccuracy can attenuate intergroup animus. A growing body of work conducted after the 2016 US President Election has found that fact-checking is successful at increasing belief accuracy (Nyhan et al., 2020; E. Porter et al., 2018; T. Wood \& Porter, 2019); however, many such interventions focus on correcting factual beliefs about the world/public policy (e.g., beliefs about crime statistics) rather than inaccurate meta-cognitive beliefs. Evidence that correcting such factual beliefs reduces actual polarization is weak, because fact-checking is less effective when the corrective information is directly counter-attitudinal (i.e., debunking personal ideology) relative to when it is unrelated to ideology (Walter et al., 2020). By contrast, addressing first-order misperceptions regarding polarization appears to be promising. For example, an informational intervention correcting inaccurate perceptions of out-party policy extremity actually reduced participants' own attitude extremity (Ahler, 2014), providing direct evidence that correcting inaccurate first-order beliefs can reduce actual polarization.

What drives first-order belief (in)accuracy? The evidence is conflicting. For example, in judging the political views of other individuals, those with more extreme political attitudes are in fact more accurate judges (Ivanov et al., 2018). By contrast, when inaccuracies are examined among perceptions of the intergroup gap in ideological positions, those with less extreme partisan positions (Van Boven et al., 2012), weaker ingroup identity (Ahler \& Sood, 2018; Enders \& Armaly, 2018), and less political sophistication (Armaly \& Enders, 2020) are more accurate. These disparate findings highlight the need for scholars to carefully disambiguate the inaccurate beliefs they are investigating, as inaccuracies across differing phenomena (e.g., factual statistics vs. the attitudes of specific others vs. the true intergroup gap in attitudes) may have distinct psychological antecedents.

Second-order beliefs. Negative and inaccurate second-order beliefs about how "they" see "us" (meta-perceptions) also play a central role in driving intergroup conflict, and have been noted as a likely contributor to "toxic" polarization (Moore-Berg, Hameiri, et al., 2020). For example, Democrats and Republicans with the most extreme ideological attitudes were the most likely to overestimate the levels of prejudice and dehumanization their respective out-party held toward them. These inaccurate meta-perceptions were, in turn, uniquely associated with a willingness to violate democratic norms in favor of ingroup loyalty (Moore-Berg, Ankori-Karlinsky, et al., 2020). Inaccurate meta-perceptions also play a role outside the domain of politics. For example, the belief that one's social group is dehumanized by the other group incites reciprocal dehumanization and support for hostile actions against outgroup members (Kteily et al., 2016). Similarly racial meta-stereotypes (what are "their" stereotypes about my group?) are associated with anxiety and decreased self-esteem (Finchilescu, 2010; Vorauer et al., 2000).

What drives meta-perception (in)accuracy? While research on first-order belief inaccuracy has tended to focus on individual explanations (e.g., information deficits, attitude extremity), research on inaccurate meta-perceptions has generally found that features of the intergroup contexts (e.g., whether the groups are in competition), rather than individual characteristics, are a strong predictor of (in)accuracy. For example, while Democrats and Republicans exhibit equally inaccurate group meta-perceptions in competitive contexts, reframing the same intergroup interactions as cooperative yields accurate meta-perceptions 
across both parties (Lees \& Cikara, 2020). Among Israelis and Palestinians, group meta-perception accuracy was associated with perceived political losses/gains after a conflict incident (a feature of the intergroup context), but not by participants' political knowledge, left-right orientation, or empathy for the outgroup (Saguy \& Kteily, 2011). Finally, the belief that one is dehumanized by outgroups (meta-dehumanization) is independent of one's prejudice toward the outgroup (Kteily et al., 2016).

These intergroup context-contingent patterns of meta-perception accuracy parallel research on dyadic meta-perceptions, where the relationships between people are generally better predictors of accuracy than attributes of the individuals. For example, meta-perceptions become significantly less accurate in competitive vs. cooperative work contexts (Eisenkraft et al., 2017), paralleling the findings from Lees \& Cikara (2020). And in relationships research, the nature of the relationship (i.e., strangers, friends, or romantic partners) is a much stronger predictor of meta-perceptive accuracy than how much individuals like each other or perceive the relationship to be of high quality (Carlson, 2016; Carlson \& Furr, 2009).

In sum, inaccurate second-order beliefs (meta-perception) represent a unique vector by which misperceived polarization leads to actual polarization via mutual reinforcement, distinct from the mechanisms associated with inaccurate first-order judgments. Therefore, understanding the methods psychologists have long used to measure meta-perception, and disentangle its many psychological components, presents a generative avenue for scholars interested in studying polarization.

\section{Measuring Inaccurate Meta-Perception: A Reanalysis}

If social scientists are to combat the cycle between misperceived polarization and actual polarization, they must be able to carefully measure the specific meta-cognitive beliefs that are inaccurate, and connect those inaccuracies to downstream consequences of interest. To highlight the power of existing psychological methods for measuring meta-cognitive accuracy, and disentangling the multiple components of judgment (in)accuracy, we turn to decades of research on the accuracy of meta-perception.

Meta-perception accuracy has long been of interest to psychology (Carlson et al., 2011; Cronbach, 1955; Kenny \& DePaulo, 1993; Laing et al., 1966). Questions of meta-accuracy have been studied largely at the individual-level, such as meta-perception in the domain of personality judgments (Vazire, 2010), close relationships (Carlson, 2016), the workplace (Eisenkraft et al., 2017), and stereotyping (Vorauer et al., 2000). From early writings on judgment accuracy (e.g., Cronbach, 1955), through the social relations model (Kenny \& Albright, 1987) to more recent methodologies like the social accuracy model (Biesanz, 2010) and truth and bias model (West \& Kenny, 2011), scholars have acknowledged that "accuracy" in social perception in truth has multiple components that can vary independently and have distinct antecedents. For example, meta-perceptions can be decomposed into judgments of how one is uniquely perceived by others (distinctive meta-accuracy), how one is perceived stereotypically (normative meta-accuracy), how one is perceived differently by different observers (differential meta-accuracy), and how one is uniquely misperceived by others (meta-insight). Moreover, these types of meta-accuracy can be operationalized as linear relationships (profile agreement/rank-order accuracy) or mean differences (directional bias). 
To demonstrate how integrating some of these distinctions into research on misperceived polarization can help us better understand and combat it, we performed a novel analysis of the data published in Lees \& Cikara (2020). We originally found that group meta-perceptions, second-order beliefs about how one's outgroup perceives the collective behavior of the ingroup, were highly negative and inaccurate among Democrats and Republicans. This negativity bias persisted across multiple competitive, but not cooperative, intergroup contexts. Critically, greater inaccuracy was associated with stronger negative first-order beliefs about outgroup motives. We found that an informational intervention informing Democrats and Republican of their inaccurate group meta-perceptions significantly reduced negative motive attributions toward the outgroup and was more effective on partisans who exhibited greater baseline inaccuracy.

Note that we examined accuracy as a matter of mean differences: are group meta-perceptions higher or lower than the average actual perception of outgroup members? Nonetheless, the structure of the data in our Experiment 4 allows for a componential (re)analysis of group meta-perceptive accuracy. Using the social accuracy model (Biesanz, 2010), we can examine accuracy as a matter of mean over/under estimation within judgment, and across judgments as the linear relationship between perceptions and their respective true values. Critically, this analysis will reveal patterns of meta-perceptive (in)accuracy not detailed in the original paper, and provide further insight into our understanding of meta-perception biases and their relationship to actual polarization.

\section{Methods}

Below we conduct a novel reanalysis of the data from Experiment 4 of Lees \& Cikara (2020). We preregistered the original collection of these data on the OSF (https://osf.io/atck5); the data and analysis code for the published results are publicly available (https://osf.io/zhysa/). We have also made our reanalysis of the original data available online (https://osf.io/4z6rc/).

\section{Sample}

The sample of 536 participants consisted of self identified Democrats and Republicans in the United States who participated in the experiment in March of 2019. Participants were recruited through Qualtrics survey panels and were quota matched to census distributions along the following variables to ensure the sample was nationally representative: age, gender, ethnicity, education, and income (see Lees \& Cikara, 2020 supplemental materials for exact quotas). The sample also had a quota for a 50/50 split of Democrats and Republicans. No participants who completed the survey are excluded from data analysis.

\section{Procedure}

Participants were randomly assigned, between-subjects, to one of three conditions: the actual perception, ingroup perception, or group meta-perception condition. Within condition, participants read 5 scenarios in randomized order, and for each scenario responded to three items. In the actual perception condition, the scenarios pertained to the participant's outgroup acting competitively toward their ingroup, and participants answered how much they disliked, 
opposed, and found politically unacceptable the behaviors in the scenarios. In the ingroup perception condition participants received the same stimuli as the actual perception condition, but were asked the perceptual items at the level of the "average" ingroup member rather than their own perceptions. In the group meta-perception condition, the scenarios pertained to the participant's ingroup acting competitively against their outgroup, and the items ask participants to judge how the average outgroup member would perceive the behaviors in the scenarios. Across all conditions, all perception measurements utilized 0-100 unipolar sliding scales. Exact survey materials can be found on the OSF here: https://osf.io/pbeaz/.

\section{Analysis}

Lees \& Cikara (2020) analyzed accuracy as the mean difference between responses in each condition (i.e., group meta-perception inaccuracy equaled the difference between GMP and actual perception conditions). Here we adopted a componential approach where accuracy was understood as both mean level over/underestimation of a given value, and the within-participant linear rank-order relationship between participant's judgments and their respective true values (Biesanz, 2010; West \& Kenny, 2011). This captures (i) point-estimate accuracy within each scenario/judgment (e.g., accuracy operationalized as whether each GMP rating is equal to its corresponding actual perception among the outgroup) and (ii) rank-order accuracy across all scenarios/judgments (e.g., accuracy operationalized as whether the relative ranking of GMPs across all judgments match the order of actual perceptions made by outgroup members).

For participants in the group meta-perception condition, the true values are the mean responses from outgroup members, within item and scenario, in the actual perception condition. For participants in the ingroup perception condition, the true values are the mean responses from ingroup members, within item and scenario, in the actual perception condition.

Drawing from the social accuracy model (Biesanz, 2010), we utilized a unified linear mixed-effect model framework to analyze accuracy in participant judgments. Participants' judgments across the group meta- and ingroup perception conditions were modeled as the dependent variable, while within-participant true values (actual-perception condition means), condition $(0=$ ingroup perceptions, $1=$ group meta-perceptions $)$, participant party affiliation $(0=$ Democrat, 1 = Republican), and the three-way interaction between them were modeled as predictors. Random intercepts for participant, scenario, and the interaction between participant and scenario were also modeled. $P$-values and degrees of freedom were calculated using Satterthwaite approximation. Both the true values and participant judgments were centered on the grand mean of the true values (Enders \& Tofighi, 2007; West \& Kenny, 2011), which orthogonalized the variables and allowed the intercept to reflect the mean difference between judgments and the truth (i.e., conceptually replicating the original analysis from Lees \& Cikara, 2020).

\section{Results}

Table 2 presents the results from the analysis of the linear relationship between perceptions and the true values of how perceivers' respective in- and outgroup actually perceived the behavior in the scenarios. In line with the findings from Lees \& Cikara (2020), the 
intercept estimate $9.26(p<0.001)$ reproduced the mean differences between the actual and ingroup perceptions conditions originally observed, and the Condition fixed-effect estimate $11.38(p<0.001)$ reproduced the mean difference between the group meta- and ingroup perceptions conditions observed in the original study.

Table 2: Accuracy of Ingroup and Group Meta-Perception

\begin{tabular}{|c|c|c|c|}
\hline \multirow[b]{2}{*}{ Predictors } & \multicolumn{3}{|c|}{ Judgment } \\
\hline & $b$ & $95 \% \mathrm{Cl}$ & $p$ \\
\hline (Intercept) & 9.26 & $4.54-13.98$ & $<0.001$ \\
\hline True Values & 0.71 & $0.53-0.90$ & $<0.001$ \\
\hline Condition [Meta-P] & 11.38 & $5.92-16.83$ & $<0.001$ \\
\hline Party [Republican] & 0.99 & $-4.83-6.81$ & 0.739 \\
\hline True Values * Condition [Meta-P] & -0.74 & $-0.96--0.52$ & $<0.001$ \\
\hline True Values * Party [Republican] & -0.21 & $-0.45-0.03$ & 0.082 \\
\hline Condition [Meta-P] * Party [Republican] & -0.41 & $-8.27-7.45$ & 0.919 \\
\hline$($ True Values * Condition [Meta-P]) * Party [Republican] & 0.40 & $0.08-0.72$ & 0.015 \\
\hline \multicolumn{4}{|l|}{ Random Effects } \\
\hline$\sigma^{2}$ & 173.06 & & \\
\hline$T_{00}$ Scenario:ID & 452.44 & & \\
\hline $\mathrm{T}_{00 \mathrm{ID}}$ & 237.52 & & \\
\hline$T_{00}$ Scenario & 6.98 & & \\
\hline ICC & 0.80 & & \\
\hline $\mathrm{N}_{\text {Scenario }}$ & 5 & & \\
\hline $\mathrm{N}_{\mathrm{ID}}$ & 366 & & \\
\hline Observations & 5479 & & \\
\hline Marginal $\mathrm{R}^{2}$ / Conditional $\mathrm{R}^{2}$ & $0.070 /$ & 815 & \\
\hline
\end{tabular}

Note: Statistically significant $p$-values less than 0.05 are bolded.

What is new is that we observed a significant linear relationship between participant judgments and the true values, suggesting that participants were accurate about the beliefs of the groups they were forecasting, however this relationship was qualified by significant two and three way interactions. As such we calculated marginal slope estimates for this linear relationship by party and condition. Figure 1 below visualizes the results. Democrats $(b=0.71$, $95 \% \mathrm{Cl}=[0.53,0.90])$ and Republican $(b=0.50,95 \% \mathrm{Cl}=[0.27,0.73])$ in the ingroup perceptions condition exhibited relative rank-order accuracy in judging the true perceptions of members of their ingroup. However, in the group meta-perception condition we observed no relative rank-order accuracy among Democrats $(b=-0.03,95 \% \mathrm{Cl}=[-0.24,0.19])$ or Republican $(b=0.16,95 \% \mathrm{Cl}=[-0.02,0.34])$ in judging the true perceptions of members of the outgroup. 
Figure 1: Three-Way Interaction

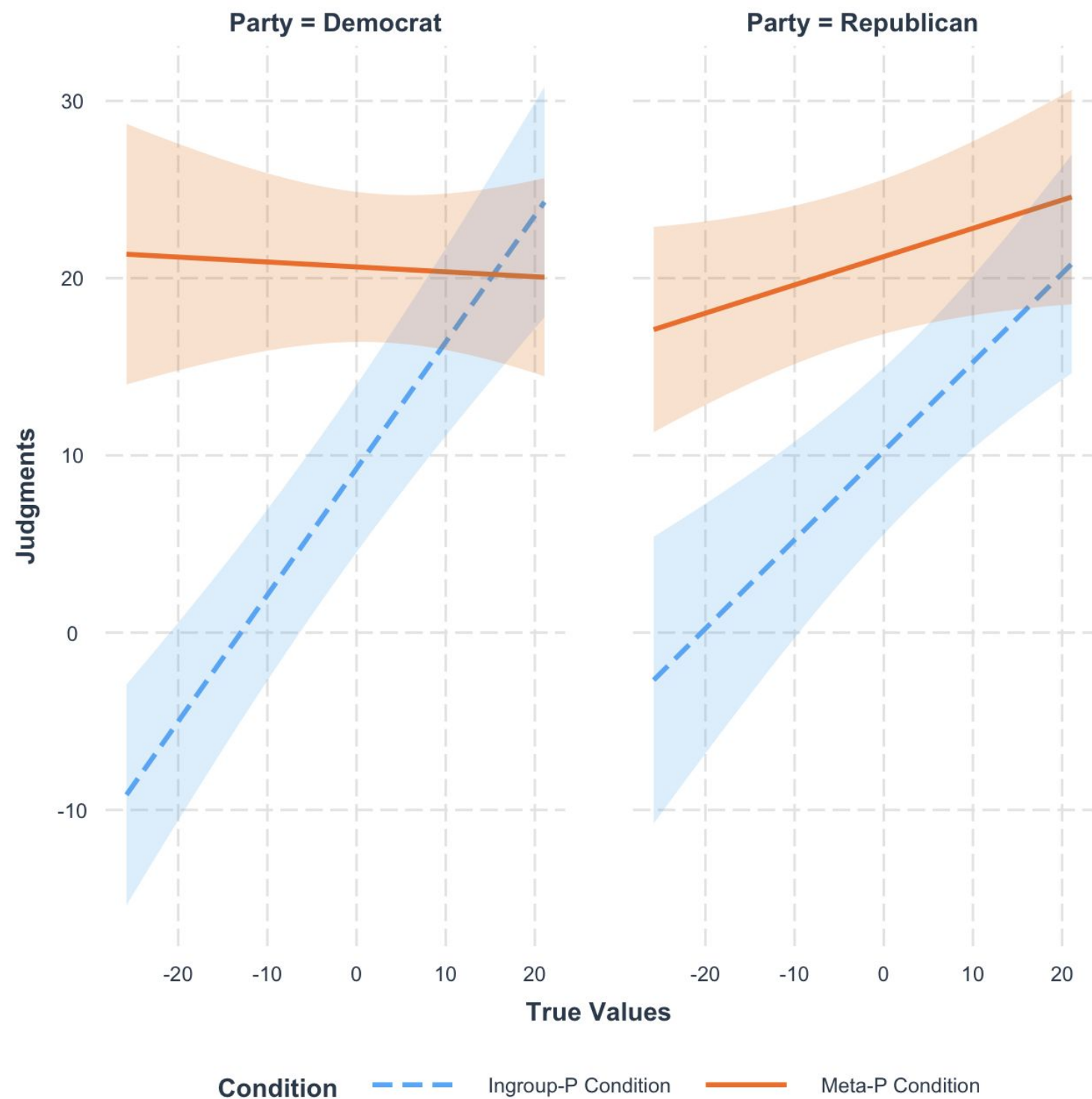

Figure 1. $\mathrm{N}=366$ ( $\mathrm{N}$ observations $=5479)$. Plot of the three-way interaction between party-identification (by panel), condition: ingroup (dashed line) vs. meta-perception (solid line), and other participants' "true" values in predicting participants' judgments. For both parties, results indicate significant and positive linear relationships between ingroup perceptions and their true values, providing evidence for rank-related accuracy; we find no such evidence for rank-related accuracy in group meta-perceptions. Error bars $95 \% \mathrm{Cls}$.

Put simply, the difference in accuracy for our judgments for the ingroup and our meta-perception judgments for the outgroup was not just a matter of degree, but a matter of kind. When estimating our ingroup's beliefs we are still sensitive to the varying severity of the scenarios and get the rank-order of judgments right; the same is not true when we are considering the beliefs of the outgroup. 


\section{Discussion}

These results highlight the critical importance, and benefit, of using a componential approach to understanding accuracy in meta-cognitive judgment. Here we replicated the original finding that group meta-perceptions are, at a mean level, overly pessimistic for forecasts of both ingroup and outgroup members. However, when examining accuracy as the linear relationship between perceptions and true values, we found that participants were accurate in their rank-order estimates of fellow ingroup members' beliefs, but not outgroup members' beliefs, despite both Democrats and Republicans having near identical actual-perceptions of the scenarios.

Rather than concluding that partisans overestimate polarization when forecasting the perceptions of all other partisans (with merely an attenuated effect size when comparing perceptions of the ingroup versus outgroup), this reanalysis suggests a qualitatively different interpretation: partisans misperceive outgroup polarization, but accurately perceive ingroup polarization, with some upward bias in their mean estimates. This more nuanced interpretation is owed to the use of componential analyses of accuracy and highlights the utility of incorporating such methods into research on (mis)perceived polarization.

This pattern also suggests that overly negative group meta-perceptions do not result from a lack of knowledge per se, rather that they result from an inability (or unwillingness) to apply the knowledge individuals already possess-in this case, the relative perceived extremity of the scenarios. Such interpretations broadly align with our assertion that misperceived polarization in the domain of second-order judgments is largely a factor of intergroup context rather than individual differences or information deficits. Thus one implication of these findings is that the links between inaccurate judgment and actual polarization reviewed above arise from a particular kind of inaccuracy: one in which one's model of the "other" is severely over-generalized. While we may have strong stereotypes about both the other party and our own, our beliefs about "us" are at least still modulated by the details of the local context. Examining how partisan extremity affects the accuracy of ingroup meta-perception is a fruitful avenue of future research, as recent work suggests ideological extremity exacerbates the inaccuracy of outgroup meta-perception among Democrats and Republicans (Moore-Berg, Ankori-Karlinsky, et al., 2020).

\section{Focus on Correcting Inaccurate Meta-Perceptions}

Integrating research on meta-cognitve inaccuracy into our understanding of polarization provides two useful insights for scholars developing interventions to correct inaccurate beliefs. The first insight is the need for componential analyses of inaccuracy. Researchers have long noted the univariate measures of judgment accuracy can be misleading (Barranti et al., 2017; Biesanz, 2010; Cronbach, 1955; D. Wood \& Furr, 2016) as they not only collapse across accuracy's multiple components, such as rank-order and mean-level accuracy, they also fail to account for known biases that affect such judgments, including normativity and stereotyping (Furr, 2008), and projection (Ames, 2004). If we wish to uncover the mechanisms driving 
misperceived polarization and use those mechanisms to develop interventions to increase belief accuracy, we need to have a precise picture of the nature of such inaccuracy.

The second insight is that informational interventions for reducing belief inaccuracy may be more effective on inaccurate second-order beliefs than on first-order beliefs. While both firstand second-order beliefs are subject to the motivation to perceive the world accurately, second-order beliefs are unique in that they are fundamentally tied to one's own, or one's group's, reputation. Individuals have a strong motivation to manage the positive impression they make on others (Bolino et al., 2008; Leary \& Kowalski, 1990), and in order to do so they need to accurately understand how they are perceived by others. This reputational motive might explain why meta-perceptions are more accurate in cooperative contexts (Eisenkraft et al., 2017; Lees \& Cikara, 2020) and among those in closer relationships (Carlson, 2016). While work on correcting inaccurate meta-perceptions in intergroup relations is still nascent, we predict that the reputational nature of meta-perception makes individuals uniquely sensitive to corrective information in a way that first-order beliefs and factual beliefs may not.

More broadly, we encourage polarization scholars to consider inaccurate meta-cognitive beliefs more centrality in their models of polarization, a call others have recently made as well (e.g., Moore-Berg, Hameiri, et al., 2020). Perhaps understandably, existing work on inaccurate political beliefs tends to focus on inaccurate factual beliefs (e.g., is climate change real, was Barack Obama born in the United States), yet interventions attempting to update such inaccurate beliefs tend to have small effects on judgment accuracy and struggle to overcome entrenched beliefs (see meta-analysis in Walter et al., 2020). While there is still much research to be done, recent work suggests corrective interventions targeting inaccurate meta-cognitive beliefs are quite effective at reducing negative intergroup outcomes (Dorison et al., 2019; Kteily et al., 2016; Lees \& Cikara, 2020). Such interventions present a fruitful avenue for attenuating the mutually-reinforcing relationship between misperceived and actual polarization.

\section{Conclusion}

Here we argue that so-called "false polarization" is best understood as inaccurate first and second-order beliefs in intergroup contexts, distinct in kind from actual perception, and better referred to as "(mis)perceived" polarization. We explicate the theoretical and empirical utility of this distinction by disambiguating first-order and second-order meta-cognitive beliefs, highlighting existing work on inaccuracies in these domains, describing the methods used for carefully measuring inaccurate meta-cognitive beliefs, and conducting a novel reanalysis of existing work on inaccurate group meta-perceptions. We believe that integrating these insights into research on polarization will help social scientists develop more effective interventions for breaking the mutually-reinforcing cycle between inaccurate intergroup beliefs and negative political outcomes. 


\section{Authors' Note}

Parts of the 'Measuring Inaccurate Meta-Perception: A Reanalysis' section are based on unpublished portions of Jeffrey Lees' dissertation, and parts of the "Sample" and "Procedure" sections are based on the text in Lees \& Cikara (2020).

\section{Additional Information}

\section{Ethics}

Experiment 4 of Lees \& Cikara (2020) was approved by Harvard University's Institutional Review Board, and all participants gave their informed consent before participating.

\section{Data Accessibility}

Data and analysis scripts for the findings presented here can be found at https://osf.io/4z6rc/.

\section{Author's Contributions}

All authors contributed substantially to the conceptualization and drafting of this article, and approved the final version. J.L. conducted the data analysis presented herein.

\section{Competing Interests}

We have no competing interests.

\section{Funding}

Work on this project by M.C. was supported by a National Science Foundation Award (no. BCS-1551559). 


\section{References}

Ahler, D. J. (2014). Self-fulfilling misperceptions of public polarization. The Journal of Politics, 76(3), 607-620. https://doi.org/10.1017/S0022381614000085

Ahler, D. J., \& Sood, G. (2018). The parties in our heads: Misperceptions about party composition and their consequences. The Journal of Politics, 80(3), 964-981.

Ames, D. R. (2004). Strategies for social inference: A similarity contingency model of projection and stereotyping in attribute prevalence estimates. Journal of Personality and Social Psychology, 87(5), 573-585. https://doi.org/10.1037/0022-3514.87.5.573

Armaly, M. T., \& Enders, A. M. (In Press). The role of affective orientations in promoting perceived polarization. Political Science Research and Methods. https://doi.org/10.1017/psrm.2020.24

Barranti, M., Carlson, E. N., \& Côté, S. (2017). How to test questions about similarity in personality and social psychology research: Description and empirical demonstration of response surface analysis. Social Psychological and Personality Science, 8(4), 465-475. https://doi.org/10.1177/1948550617698204

Biesanz, J. C. (2010). The social accuracy model of interpersonal perception: Assessing individual differences in perceptive and expressive accuracy. Multivariate Behavioral Research, 45(5), 853-885. https://doi.org/10.1080/00273171.2010.519262

Blatz, C. W., \& Mercier, B. (2018). False polarization and false moderation: Political opponents overestimate the extremity of each other's ideologies but underestimate each other's certainty. Social Psychological and Personality Science, 9(5), 521-529. https://doi.org/10.1177/1948550617712034

Bolino, M. C., Kacmar, K. M., Turnley, W. H., \& Gilstrap, J. B. (2008). A multi-level review of impression management motives and behaviors. Journal of Management, 34(6), 1080-1109. https://doi.org/10.1177/0149206308324325

Carlson, E. N. (2016). Meta-accuracy and relationship quality: Weighing the costs and benefits of knowing what people really think about you. Journal of Personality and Social Psychology, 111(2), 250-264. https://doi.org/10.1037/pspp0000107

Carlson, E. N., \& Furr, R. M. (2009). Evidence of differential meta-accuracy: People understand the different impressions they make. Psychological Science, 20(8), 1033-1039.

Carlson, E. N., Vazire, S., \& Furr, R. M. (2011). Meta-insight: Do people really know how others see them? Journal of Personality and Social Psychology, 101(4), 831-846. https://doi.org/10.1037/a0024297

Cronbach, L. J. (1955). Processes affecting scores on "understanding of others" and "assumed similarity." Psychological Bulletin, 52(3), 177-193. https://doi.org/10.1037/h0044919

Dorison, C. A., Minson, J. A., \& Rogers, T. (2019). Selective exposure partly relies on faulty affective forecasts. Cognition. https://doi.org/10.1016/j.cognition.2019.02.010

Druckman, J. N., Klar, S., Krupnikov, Y., Levendusky, M., \& Ryan, J. B. (2019). The illusion of affective polarization. https://www.ipr.northwestern.edu/documents/working-papers/2019/wp-19-25.pdf

Eisenkraft, N., Elfenbein, H. A., \& Kopelman, S. (2017). We know who likes us, but not who competes against us: Dyadic meta-accuracy among work colleagues. Psychological Science, 28(2), 233-241.

Enders, A. M., \& Armaly, M. T. (2018). The differential effects of actual and perceived polarization. Political Behavior, 41(3), 815-839.

Enders, C. K., \& Tofighi, D. (2007). Centering predictor variables in cross-sectional multilevel 
models: A new look at an old issue. Psychological Methods, 12(2), 121-138.

https://doi.org/10.1037/1082-989X.12.2.121

Federico, C. M. (2020). When do psychological differences predict political differences?

Engagement and the psychological bases of political polarization. In Political

Polarization. Routledge.

Finchilescu, G. (2010). Intergroup anxiety in interracial interaction: The role of prejudice and metastereotypes. Journal of Social Issues, 66(2), 334-351.

https://doi.org/10.1111/j.1540-4560.2010.01648.x

Furr, R. M. (2008). A framework for profile similarity: Integrating similarity, normativeness, and distinctiveness. Journal of Personality, 76(5), 1267-1316. https://doi.org/10.1111/j.1467-6494.2008.00521.x

Ivanov, I., Muller, D., Delmas, F., \& Wänke, M. (2018). Interpersonal accuracy in a political context is moderated by the extremity of one's political attitudes. Journal of Experimental Social Psychology, 79, 95-106. https://doi.org/10.1016/j.jesp.2018.07.001

lyengar, S., Lelkes, Y., Levendusky, M., Malhotra, N., \& Westwood, S. J. (2019). The origins and consequences of affective polarization in the United States. Annual Review of Political Science, 22(1), 129-146. https://doi.org/10.1146/annurev-polisci-051117-073034

Kenny, D. A., \& Albright, L. (1987). Accuracy in interpersonal perception: A social relations analysis. Psychological Bulletin, 102(3), 390-402.

Kenny, D. A., \& DePaulo, B. M. (1993). Do people know how others view them? An empirical and theoretical account. Psychological Bulletin, 114(1), 145-161.

Kteily, N., Hodson, G., \& Bruneau, E. (2016). They see us as less than human: Metadehumanization predicts intergroup conflict via reciprocal dehumanization. Journal of Personality and Social Psychology, 110(3), 343-370. https://doi.org/10.1037/pspa0000044

Laing, R. D., Phillipson, H., \& Lee, A. R. (1966). Interpersonal perception: A theory and method of research. Springer.

Leary, M. R., \& Kowalski, R. M. (1990). Impression management: A literature review and two-component model. Psychological Bulletin, 107(I), 34-47. https://doi.org/10.1037/0033-2909.107.1.34

Lees, J., \& Cikara, M. (2020). Inaccurate group meta-perceptions drive negative out-group attributions in competitive contexts. Nature Human Behaviour, 4(3), 279-286. https://doi.org/10.1038/s41562-019-0766-4

Levendusky, M. S., \& Malhotra, N. (2016). (Mis)perceptions of partisan polarization in the American public. Public Opinion Quarterly, 80(S1), 378-391. https://doi.org/10.1093/poq/nfv045

Mason, L. (2018). Ideologues without issues: The polarizing consequences of ideological identities. Public Opinion Quarterly, 82(S1), 866-887. https://doi.org/10.1093/poq/nfy005

Moore-Berg, S. L., Ankori-Karlinsky, L.-O., Hameiri, B., \& Bruneau, E. (2020). Exaggerated meta-perceptions predict intergroup hostility between American political partisans. Proceedings of the National Academy of Sciences, 117(26), 14864-14872. https://doi.org/10.1073/pnas.2001263117

Moore-Berg, S. L., Hameiri, B., \& Bruneau, E. (2020). The prime psychological suspects of toxic political polarization. Current Opinion in Behavioral Sciences, 34, 199-204. https://doi.org/10.1016/j.cobeha.2020.05.001

Navajas, J., Álvarez Heduan, F., Garrido, J. M., Gonzalez, P. A., Garbulsky, G., Ariely, D., \& Sigman, M. (2019). Reaching consensus in polarized moral debates. Current Biology, 
29(23), 4124-4129.e6. https://doi.org/10.1016/j.cub.2019.10.018

Nyhan, B., Porter, E., Reifler, J., \& Wood, T. J. (2020). Taking fact-checks literally but not seriously? The effects of journalistic fact-checking on factual beliefs and candidate favorability. Political Behavior, 42(3), 939-960. https://doi.org/10.1007/s11109-019-09528-x

Porter, E., Wood, T. J., \& Kirby, D. (2018). Sex trafficking, Russian infiltration, birth certificates, and pedophilia: A survey experiment correcting fake news. Journal of Experimental Political Science, 5(2), 159-164. https://doi.org/10.1017/XPS.2017.32

Porter, T., \& Schumann, K. (2018). Intellectual humility and openness to the opposing view. Self and Identity, 17(2), 139-162. https://doi.org/10.1080/15298868.2017.1361861

Pronin, E., Pucio, C., \& Ross, L. (2002). Understanding misunderstanding: Social psychological perspectives. In T. Gilovich, D. W. Griffin, \& D. Kahneman (Eds.), Heuristics and biases: The psychology of intuitive judgment (pp. 636-665). Cambridge University Press. https://doi.org/10.1017/CBO9780511808098.038

Robinson, R. J., Keltner, D., Ward, A., \& Ross, L. (1995). Actual versus assumed differences in construal: "Naive realism" in intergroup perception and conflict. Journal of Personality and Social Psychology, 68(3), 404-417. https://doi.org/10.1037/0022-3514.68.3.404

Rollwage, M., Dolan, R. J., \& Fleming, S. M. (2018). Metacognitive failure as a feature of those holding radical beliefs. Current Biology, 28(24), 4014-4021.e8. https://doi.org/10.1016/j.cub.2018.10.053

Saguy, T., \& Kteily, N. (2011). Inside the opponent's head: Perceived losses in group position predict accuracy in metaperceptions between groups. Psychological Science, 22(7), 951-958.

Simas, E. N., Clifford, S., \& Kirkland, J. H. (2020). How empathic concern fuels political polarization. American Political Science Review, 114(1), 258-269. https://doi.org/10.1017/S0003055419000534

Stanley, M. L., Henne, P., Yang, B. W., \& De Brigard, F. (2019). Resistance to position change, motivated reasoning, and polarization. Political Behavior. https://doi.org/10.1007/s11109-019-09526-z

Stone, D. F. (2020). Just a big misunderstanding? Bias and bayesian affective polarization. International Economic Review, 61(1), 189-217. https://doi.org/10.1111/iere.12421

Van Boven, L., Judd, C. M., \& Sherman, D. K. (2012). Political polarization projection: Social projection of partisan attitude extremity and attitudinal processes. Journal of Personality and Social Psychology, 103(1), 84-100. https://doi.org/10.1037/a0028145

Vazire, S. (2010). Who knows what about a person? The self-other knowledge asymmetry (SOKA) model. Journal of Personality and Social Psychology, 98(2), 281-300. https://doi.org/10.1037/a0017908

Vorauer, J. D., Hunter, A., Main, K., \& Roy, S. (2000). Meta-stereotype activation: Evidence from indirect measures for specific evaluative concerns experienced by members of dominant groups in intergroup interaction. Journal of Personality and Social Psychology, 78(4), 690-707. https://doi.org/10.1037/0022-3514.78.4.690

Walter, N., Cohen, J., Holbert, R. L., \& Morag, Y. (2020). Fact-checking: A meta-analysis of what works and for whom. Political Communication, 37(3), 350-375. https://doi.org/10.1080/10584609.2019.1668894

West, T. V., \& Kenny, D. A. (2011). The truth and bias model of judgment. Psychological Review, 118(2), 357-378. https://doi.org/10.1037/a0022936

Westfall, J., Van Boven, L., Chambers, J. R., \& Judd, C. M. (2015). Perceiving political polarization in the United States: Party identity strength and attitude extremity 
exacerbate the perceived partisan divide. Perspectives on Psychological Science, 10(2), 145-158. https://doi.org/10.1177/1745691615569849

Wood, D., \& Furr, R. M. (2016). The correlates of similarity estimates are often misleadingly positive: The nature and scope of the problem, and some solutions. Personality and Social Psychology Review, 20(2), 79-99. https://doi.org/10.1177/1088868315581119

Wood, T., \& Porter, E. (2019). The elusive backfire effect: Mass attitudes' steadfast factual adherence. Political Behavior, 41(1), 135-163. https://doi.org/10.1007/s11109-018-9443-y

Yang, J., Rojas, H., Wojcieszak, M., Aalberg, T., Coen, S., Curran, J., Hayashi, K., lyengar, S., Jones, P. K., Mazzoleni, G., Papathanassopoulos, S., Rhee, J. W., Rowe, D., Soroka, S., \& Tiffen, R. (2016). Why are "others" so polarized? Perceived political polarization and media use in 10 countries. Journal of Computer-Mediated Communication, 21(5), 349-367. https://doi.org/10.1111/jcc4.12166 